\title{
Rare Case Of Endometrial Hyperplasia Following Unsupervised Prolonged Use Of Ormiloxifene.
}

\author{
Dr. Adusumilli Padmaja ${ }^{1}$, Assistant Professor, Dr. Prashanthi Vemulapalli ${ }^{2}$, \\ Asst. Professor, Dr. Kakarla Jaya Prada Devi ${ }^{3}$, Associate Professor \\ 1,2,3, (Dept. of OBG, Dr. PSIMS \& RF, Chinoutpalli, AP, India)
}

\begin{abstract}
Ormiloxifene is a non steroidal selective estrogen receptor modulator belonging to benzopyran group. Its use as a contraceptive, post coital pill, and as a drug of choice in management of menorrhagia, Dysfunctional Uterine Bleeding is well documented. Duration of treatment and its long term effects have to be evaluated further. We are reporting a rare case of endometrial hyperplasia following unsupervised use of ormiloxifene for prolonged duration, thereby emphasizing follow up of patients on ormiloxifene therapy.
\end{abstract}

Key words: Ormiloxifene, Endometrial hyperplasia, follow up.

\section{Introduction}

Ormiloxifene is a nonsteriodal selective estrogen receptor modulator belonging to benzopyran group ${ }^{1}$. Use of ormiloxifene as a weekly contraceptive \& in the treatment of menorrhagia, Dysfuncitonal Uterine Bleeding, mastalgia is well known ${ }^{2}$. The drug acts by modulating the estrogen receptors on endometrium there by decidualizing the endometrium ${ }^{3}$. It is given in a dose of $60 \mathrm{mg}$ twice weekly for 3 months \& weekly for next 3 months. The drug is metabolized in liver and has a half life of 170 hours. Highest concentration of drug is seen in uterus next only to liver ${ }^{4}$. Common contraindications are hepatic dysfunction, pregnancy, lactation, chronic illness, PCOS. Common side effects are nausea, vomiting \& weight gain. Endometrial hyperplasia has not been documented as an adverse effect ${ }^{5}$. Centchroman, Saheli, Novex - DS, Sevista are several trade names of the drug.

\section{Case report}

Miss X aged 18 years, unmarried, presented to Gynaec OP, Dr. PSIMS \& RF with complaints of excess menstrual flow from last 10 days. Her present cycle was preceeded by 2 months of amenorrhoea. She attained menarche at the age of 14years. Her initial cycles were irregular, cycle duration lasting between $20-45$ days. Eventually her cycles had become menorrhagic for which she had consulted a gynaecologist two years ago who put her on Ormiloxifene $60 \mathrm{mg}$ twice wkly for 3 months \& weekly there on for another three months. Patient was asked to followup after 3 months, however patient continued the drug unsupervised for the last 2 years as her cycles had become oligomenorrhoec, and now presented to Dr. PSIMS \& RF with abnormal uterine bleeding.

On examination, patient general condition was stable. Her BMI was 17, vitals stable, pallor present, P/A soft, vulvovaginal examination: bleeding present, hymen intact.

Patient was investigated, her UPT was negative, $\mathrm{Hb} 7 \mathrm{gm} \%$, B Positive, Ultrasound revealed bulky uterus with 8 x $4 \mathrm{~cm}$ hyperechoic area with increased AV channels within it. Endometrium was not separately made out as seen in fig 1 .

MRI revealed large enhancing tissue/mass seen in endometrial cavity. Differential diagnosis of endometrial hyperplasia/polyp was given. D \& C was done to know type of hyperplasia and to rule out endometrial carcinoma as shown in fig 2.

HPE revealed simple endometrial hyperplasia without atypia.

Patient was put on cyclical progesterone and discharged. Further follow up scan after six months showed normal uterus with normal endometrial thickness. Patient was educated about Ormiloxifene and its side effects. Progesterone was discontinued and she was asked to report six months later. 


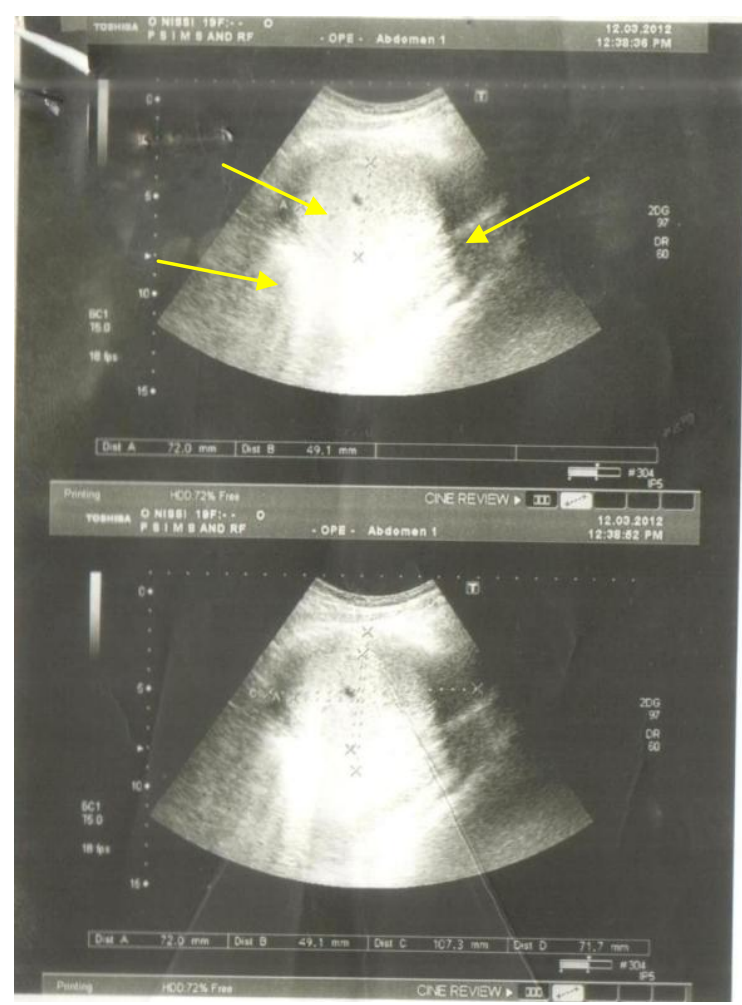

Fig:1 ultrasound picture showing uterus with hyperechoic area measuring 7.9 x $4.2 \mathrm{cms}$. Endometrium not separately made out as shown between yellow arrows.

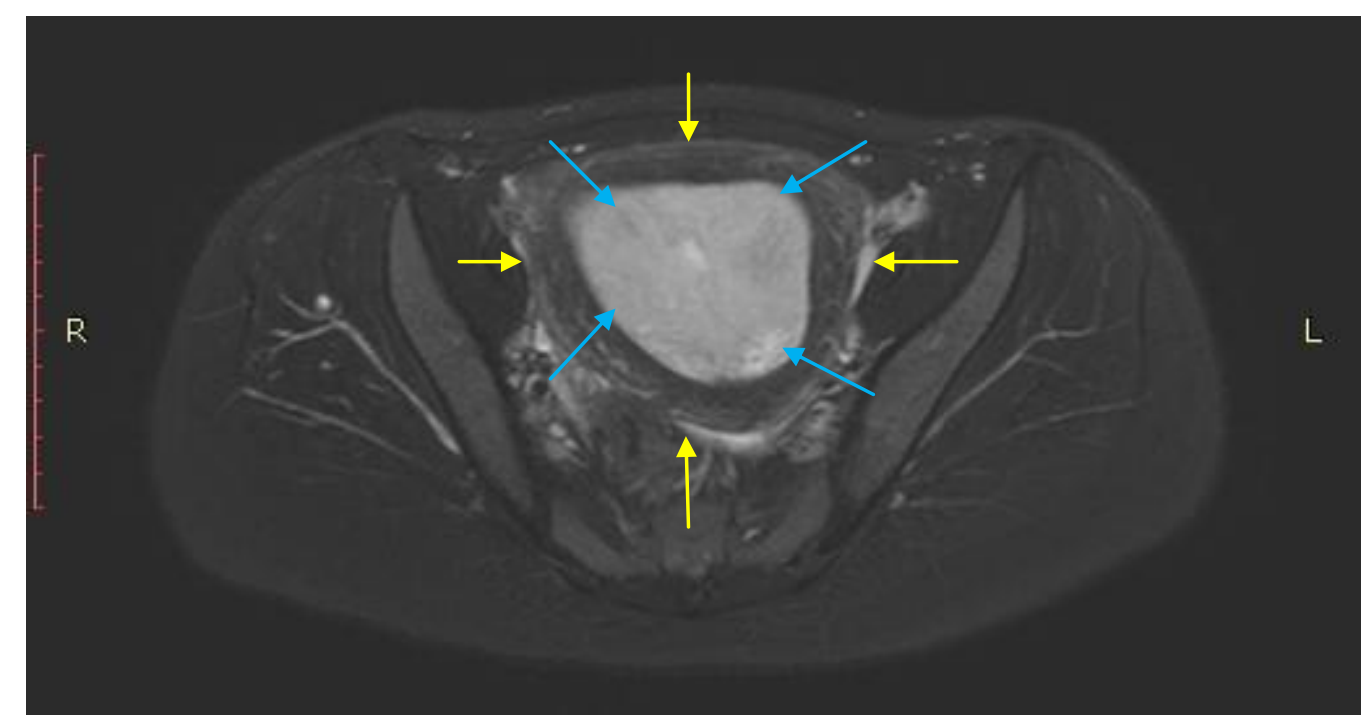

Fig 2 MRI picture showing uterus $13.5 \times 9.2 \times 7.0$ shown between yellow arrows. Endometrium measuring $11 \times$ $7 \times 4.7$ between blue arrows.

\section{Conclusion}

Ormiloxifene is a SERM and its antiestrogenic property on endometrium has been used in the treatment of menstrual abnormalities. Patients who are put on ormiloxifene should be educated about the possible side effects of the drug. Though the drug has antiestrogenic property on endometrium, its long term use has resulted in endometrial hyperplasia as seen in the above case. Though the result cannot be concluded by one case there is a need to evaluate the long term effects of the drug.

\section{Acknowledgement}

Staff members, Dept of OBG, Dr. PSIMS \& RF.

Dept. of Radiology, Dr. PSIMS \& RF 


\section{References}

[1]. steven R.Goldstein, suresh siddhanthi,et al human reproduction update 2000,volume.6 no.3pp.212-224

[2]. Kriplami A, Kulshrestha V, Agarwal N. Efficacy and safety of ormeloxifene in the management of menorrhagia: A pilot study. The journal of obstetrics and gynecol research 2009; 35 (4): $746-52$

[3]. Biswas SC, Saha SK, Bag TS, Ghosh Roy SC, Roy AC, Kabiraj SP. Ormeloxifene: A selective estrogen receptor modulator for treatment of dysfunctional menorrhagia. J Obstet Gynecol Ind 2004;54(1):56-59.

[4]. steven R.Goldstein, suresh siddhanthi,et al human reproduction update 2000,volume.6 no.3pp.212-224

[5]. Eurj contracept reprod health care. 2011 oct;16 (5): 403 - 6. Doi:10.3109/13625187.2011.595851. Epub 2011 Jul 21. Malhotra KP, Sherpa M, Bhatia A. 